\title{
Perinatal characteristics and risk of polio among Swedish twins
}

\author{
Wei Perng ${ }^{\mathrm{a}}$, Sven Cnattingius ${ }^{\mathrm{b}}$, Anastasia Iliadou ${ }^{\mathrm{c}}$ and Eduardo Villamor ${ }^{\mathrm{a}}$ \\ ${ }^{a}$ Department of Epidemiology, University of Michigan School of Public Health, Ann Arbor, MI, USA, ${ }^{b}$ Clinical Epidemiology Unit, Department \\ of Medicine, and ${ }^{c}$ Department of Medical Epidemiology and Biostatistics, Karolinska Institute and Hospital, Stockholm, Sweden
}

Correspondence:

Wei Perng, Center For Social Epidemiology \& Population Health, Room 2665, 1415 Washington Heights, 2nd Floor Tower, University of Michigan School of Public Health, Ann Arbor, MI 48109-2029, USA.

E-mail: perngwei@umich.edu

\section{Summary}

Perng W, Cnattingius S, Iliadou A, Villamor E. Perinatal characteristics and risk of polio among Swedish twins. Paediatric and Perinatal Epidemiology 2012; 26: 218-225.

Prenatal exposure to adverse environmental conditions is related to increased adult mortality in regions where infections are highly prevalent, yet there is little evidence of the impact of perinatal conditions on the risk of severe infections throughout life. Using prospectively collected data from 21604 like-sexed Swedish twins of known zygosity born in 1926-1958, we examined the risk of polio in relation to perinatal characteristics using cohort and nested co-twin case-control analyses. Polio incidence was determined through an interview in 1998, and linkage with the Swedish national inpatient and death registries. There were 133 cases of polio. In the cohort analysis, birth length, birthweight and head circumference were positively associated with polio risk. After adjustment for sex, birth year, gestational age at birth and within-twin pair correlations, twins of shortest length $(<44 \mathrm{~cm}$ ) had a $67 \%$ ([95\% CI: $6 \%, 88 \%] ; P=0.04)$ lower risk of polio compared with the reference group $(47-49 \mathrm{~cm})$. After additional adjustment for birth length, every $100 \mathrm{~g}$ increase in birthweight was related to a $34 \%$ increased risk of polio ([95\% CI: $-1 \%, 82 \%] ; P=0.06$ ), and every $10-\mathrm{mm}$ increase in head circumference was related to a $17 \%$ greater risk of polio ( $[95 \% \mathrm{CI}$ : $5 \%, 31 \%] ; P=0.004)$. In co-twin control analyses among 226 disease-discordant twins, birth length, birthweight and head circumference were $0.3 \mathrm{~cm}(P=0.19), 84 \mathrm{~g}(P=0.07)$ and $3 \mathrm{~mm}(P=0.08)$ higher in cases than controls, respectively. Similar associations were observed among monozygotic $(n=84)$ and dizygotic $(n=142)$ twins. These findings suggest that early intrauterine growth restriction may be inversely related to the incidence of polio.

Keywords: polio, birthweight, birth length, head circumference, intrauterine growth, twins.

\section{Introduction}

Prenatal exposure to adverse environmental conditions has been related to adult mortality in world regions where severe infections are highly prevalent. Moore et al. reported that people born during the nutritionally debilitating hungry season in the Gambia had a greater risk of early mortality as young adults compared with those born during the harvest season. ${ }^{1}$ Because infections were among the most frequent causes of death in these settings, researchers postulated that intrauterine exposure to malnutrition programmed ways in which the immune system responds to infectious challenges. ${ }^{1}$ This hypothesis would be lent support if indicators of maternal exposure to nutri- tional insults during pregnancy were associated with the incidence of infections in the offspring.

Studies have found links between fetal growth and immunological fitness in adulthood. ${ }^{2}$ We have previously reported that birthweight, an indicator of intrauterine growth, was inversely related to the incidence of tuberculosis in monozygotic twins. ${ }^{3}$ Although birthweight is an imperfect measure of the intrauterine environment, this finding lends support to the hypothesis that prenatal exposures leading to suboptimal prenatal growth might influence the type and strength of the immune response to severe infections later in life. However, the potential 'programming' of fetal immunity might depend on the type of immune response elicited by the infectious agent. Tuberculosis 
elicits a strong innate cellular immune response, ${ }^{4}$ but studies linking perinatal exposures to the incidence of infections that predominantly require humoral responses are lacking. Low birthweight has been related to increased incidence of bacterial infections that elicit strong B cell-dependent humoral responses, such as meningococcal infections, ${ }^{5}$ and to weakened B cell-dependent antibody production against polysaccharide antigens. ${ }^{2,6}$ Yet, the potential role of intrauterine undernutrition on postnatal risk of viral infections is unknown. Poliomyelitis is a highly infectious viral disease which mainly affects young children and is still of major concern in countries of West Africa and South Asia. ${ }^{7}$ We examined the association between anthropometric characteristics at birth and the risk of polio using prospectively collected information from 21604 likesexed Swedish twins with known zygosity. We hypothesised that anthropometric indicators of intrauterine growth would be inversely associated with risk of polio.

\section{Methods}

\section{Study population}

The source population for this study was the Swedish Twin Registry (STR) which includes 37392 like-sexed twins born in Sweden between 1926 and $1958 .{ }^{8}$ For this analysis, the data set was restricted to twin pairs with known zygosity ( $n=32580)$. Zygosity was determined through questions on physical resemblance in childhood. A DNA validation study in a subsample of 199 twin pairs found that the zygosity classification based on resemblance was $99 \%$ accurate. $^{8}$

\section{Outcome}

Ascertainment of disease incidence using this source population has been described previously. ${ }^{3}$ In brief, the outcome of interest in this study is polio incidence, which was ascertained through three sources: the Screening Across the Lifespan Twin (SALT) study, ${ }^{9}$ the Swedish National Inpatient Registry and the Swedish Cause of Death Registry. The SALT study was a telephone interview conducted in 1998, ${ }^{10}$ in which 23545 of the twins with known zygosity participated. During this interview, participants were asked questions about their past and current health status. Twins in the STR with known zygosity were also cross-linked with the Swedish National Inpatient and Cause of Death Registries, using a unique national identification number that is assigned to all residents in Sweden at birth or upon immigration. We defined polio cases as participants who responded 'yes' in the SALT interview to the question 'Have you ever been told that you have polio by a doctor or at a doctor's office or hospital?', or when they appeared in the Inpatient or Cause of Death Registries with a diagnosis that corresponded to acute poliomyelitis, late effects of poliomyelitis, postpoliomyelitis syndrome or sequelae of polio according to the International Classification of Disease (ICD). These codes were: for the ICD-7th edition, 080 and 081; for the ICD-8th edition, 040-044; for the ICD-9th edition, 045 and 138; or for the ICD-10th edition, A80, B91 and G14. Concordance between the self-report in the interview and the diagnoses in the registries could not be determined, because most polio cases (selfreported) occurred before the registries were established. The Inpatient Registry was started in 1964 and reached nation-wide coverage in 1987, ${ }^{11}$ and the Causes of Death Registry was established in 1961.

\section{Exposures}

Among STR participants, perinatal information was retrieved from original medical birth records, which are maintained at local delivery archives throughout Sweden, as required by law. Correct birth identification for each twin within a pair was ensured by restricting to twin pairs who were both baptised and named at birth or, among participants in the 1998 interview, to those who agreed on birth order. Agreement on birth order between the birth records and SALT study is $95 \%$ for twins baptised and named at birth. The main exposures of interest in our study were birth length, birthweight and head circumference (HC) as recorded in the birth records. Gestational age was defined according to the date of the last menstrual period. Parental socioeconomic status was classified according to occupation, following the categories recommended by Statistics Sweden. ${ }^{12}$ The highest socio-economic status of the parents was used to define socio-economic status at birth.

Medical birth records with correct identification of individual twins were obtained for 23711 (73\%) of the 32580 like-sexed twins with known zygosity. Of these twins, 23600 had valid birthweight information (birthweight values within 5 standard deviations above or below the sex- and gestational age-specific distribution), and 22594 also had information on polio diagnosis. The final study group for these analyses 
comprised 21604 intact twin pairs of known zygosity, who also had information on polio diagnosis.

\section{Cohort analysis}

First, we ascertained the incidence of polio with respect to indicators of intrauterine growth and maternal characteristics using a cohort design. Relative risks and $95 \%$ confidence intervals [ $95 \% \mathrm{CI}$ ] were estimated using binomial regression models with the log-link function (PROC GENMOD; SAS Institute, Inc., Cary, NC, USA). In these models, we specified an exchangeable correlation matrix to account for within-twin pair correlations. Adjusted estimates were obtained from multivariable models that included sex, birth year and gestational age at birth as covariates. Models for birthweight were also adjusted for birth length. We also calculated adjusted relative risk associated with continuous differences in each anthropometric indicator (1-cm birth length, 500-g birthweight and 10-mm HC).

\section{Co-twin control analyses}

We conducted a nested co-twin control analysis ${ }^{13}$ to evaluate the associations of birth length, birthweight and HC, with risk of polio independent of genetic and shared environmental influences. We selected twin pairs who were discordant for polio, with the healthy twin serving as a matched control for the twin with polio. Case-control differences in the distribution of anthropometric characteristics at birth were compared with the use of the Wilcoxon matched-pairs rank-sum test. Next, we estimated odds ratios and $95 \%$ CI for polio risk according to each anthropometric characteristic with the use of conditional logistic regression. These analyses were performed separately for monozygotic $(n=84)$ and dizygotic $(n=142)$ twin pairs.

The matched analyses minimise confounding by shared intrauterine exposures, maternal factors, and general childhood and adolescent environment, as $97 \%$ of the twins reported that they lived with their twin sibling until 15 years of age. Since genetic factors are fully controlled for when comparing monozygotic but not dizygotic twin siblings, a comparison of the magnitude of associations observed with monozygotic and dizygotic twin pairs provides insight into confounding by genetic factors.

All analyses were carried out with SAS, version 9.2 (SAS Institute). The study was approved by the research ethics committee of the Karolinska Institute.

\section{Results}

Mean \pm SD birthweight, birth length and HC were $2637 \pm 504 \mathrm{~g}, 47.6 \pm 2.8 \mathrm{~cm}$ and $329 \pm 18 \mathrm{~mm}$, respectively. There were 133 cases of polio $(0.62 \%)$. In univariable analysis, polio incidence did not differ by sex, but was inversely related to year of birth $(P<0.0001$; Table 1). Incidence of polio was lowest for shortest and leanest babies. There was a positive trend between HC and polio incidence. After adjustment for sex, birth year, gestational age at birth and within-twin pair correlations, twins of shortest birth length $(<44 \mathrm{~cm})$ had a $67 \%$ ([95\% CI: $6 \%, 88 \%] ; P=0.04$ ) lower risk of polio compared with the reference group $(47-49 \mathrm{~cm}$; Table 2). Every 500-g birthweight was associated with a $34 \%$ increased risk of polio ([95\% CI: $-1 \%, 82 \%]$; $P=0.06$ ), whereas each increase of $10-\mathrm{mm} \mathrm{HC}$ was associated with a significant $17 \%$ increased risk of polio ([95\% CI: 5\%, 31\%]; $P=0.004$; Table 2).

In the co-twin case-control analysis conducted among 226 twins discordant for polio (Table 3), mean birth length, birthweight and HC were $0.3 \mathrm{~cm}$ $(P=0.19), 84 \mathrm{~g}(P=0.07)$ and $3 \mathrm{~mm}(P=0.08)$ higher for cases than controls, respectively. Associations were comparable among both monozygotic $(n=84)$ and dizygotic twins $(n=142)$, although the observed differences were not statistically significant.

\section{Discussion}

Risk of polio was positively related to measures of fetal growth, including birth length and $\mathrm{HC}$, in this large cohort of Swedish twins. To evaluate whether associations observed in the cohort analyses were confounded by genetic or environmental factors, we conducted co-twin control analyses. In these analyses, similar results were found, although they were not statistically significant.

There are a few possible non-causal explanations for these findings. First, although the cohort was large, statistical power was likely to have been limited by the low incidence of polio in Sweden. We noted that $6.8 \%$ $(n=1472)$ of our study population was born after the introduction of the poliovirus vaccine in Sweden in $1957 .{ }^{14}$ The diminished incidence of polio for participants born 1957-1958 (0.2\%) would have contributed to the low number of cases. Thus, it is not possible to preclude the likelihood that the findings were due to chance. Second, while we adjusted for key potential confounders in our analyses, residual confounding by unmeasured perinatal characteristics is possible. 


\begin{tabular}{|c|c|c|c|c|}
\hline Variable & $n$ & $\begin{array}{l}\text { Polio } \\
\%(n)\end{array}$ & $\mathrm{URR}^{\mathrm{a}}[95 \% \mathrm{CI}]^{\mathrm{a}}$ & $P^{\mathrm{b}}$ \\
\hline Overall & 21604 & $0.61(133)$ & & \\
\hline Gender & & & & 0.85 \\
\hline Male & 10204 & $0.63(64)$ & 1.00 Reference & \\
\hline Female & 11400 & $0.61(69)$ & $0.97[0.67,1.39]$ & \\
\hline Birth year & & & & $<0.0001$ \\
\hline 1926-1929 & 1316 & $1.82(24)$ & $3.61[2.14,6.07]$ & \\
\hline 1930-1939 & 4468 & $0.94(42)$ & $1.86[1.19,2.91]$ & \\
\hline 1940-1949 & 8698 & $0.51(44)$ & 1.00 Reference & \\
\hline 1950-1958 & 7122 & $0.32(23)$ & $0.64[0.37,1.09]$ & \\
\hline Gestational age, weeks & & & & 0.49 \\
\hline $31-34$ & 2797 & $0.64(18)$ & $1.08[0.62,1.89]$ & \\
\hline $35-36$ & 4327 & $0.58(25)$ & $0.96[0.59,1.56]$ & \\
\hline $37-41$ & 12672 & $0.63(80)$ & 1.00 Reference & \\
\hline $42-45$ & 768 & $0(0)$ & - & \\
\hline Missing & 1040 & $0.96(10)$ & & \\
\hline Birth length, $\mathrm{cm}$ & & & & 0.32 \\
\hline$<44$ & 1791 & $0.22(4)$ & $0.36[0.13,1.00]$ & \\
\hline $44-46$ & 4961 & $0.71(35)$ & $1.21[0.79,1.86]$ & \\
\hline $47-49$ & 9368 & $0.62(58)$ & 1.00 Reference & \\
\hline $50-51$ & 1050 & $0.69(28)$ & $1.21[0.77,1.88]$ & \\
\hline$\geq 52$ & 1286 & $0.47(6)$ & $0.83[0.36,1.89]$ & \\
\hline Missing & 148 & $1.35(2)$ & & \\
\hline Birthweight, g & & & & 0.37 \\
\hline$<2000$ & 2132 & $0.28(6)$ & $0.48[0.21,1.10]$ & \\
\hline $2000-2499$ & 6158 & $0.71(44)$ & $1.14[0.75,1.72]$ & \\
\hline $2500-2999$ & 7813 & $0.61(48)$ & 1.00 Reference & \\
\hline $3000-3499$ & 4444 & $0.65(29)$ & $1.08[0.68,1.73]$ & \\
\hline$\geq 3500$ & 1057 & $0.57(6)$ & $0.96[0.41,2.24]$ & \\
\hline Head circumference, mm & & & & 0.08 \\
\hline$\leq 319$ & 4383 & $0.41(18)$ & $0.70[0.38,1.29]$ & \\
\hline $320-329$ & 4007 & $0.65(26)$ & $1.03[0.60,1.77]$ & \\
\hline $330-339$ & 4901 & $0.59(29)$ & 1.00 Reference & \\
\hline $340-349$ & 4366 & $0.69(30)$ & $1.20[0.73,1.99]$ & \\
\hline$\geq 350$ & 3305 & $0.73(24)$ & $1.19[0.69,2.06]$ & \\
\hline Missing & 642 & $0.93(6)$ & & \\
\hline Maternal age, years & & & & 0.53 \\
\hline$<20$ & 586 & $0.51(3)$ & $0.94[0.28,3.16]$ & \\
\hline $20-24$ & 3666 & $0.55(20)$ & 1.00 Reference & \\
\hline $25-29$ & 6464 & $0.63(41)$ & $1.16[0.66,2.05]$ & \\
\hline $30-34$ & 5920 & $0.61(36)$ & $1.11[0.63,1.97]$ & \\
\hline$\geq 35$ & 4946 & $0.67(33)$ & $1.22[0.68,2.20]$ & \\
\hline Missing & 22 & $0(0)$ & & \\
\hline Maternal parity & & & & 0.50 \\
\hline Primipara & 7000 & $0.67(47)$ & 1.00 Reference & \\
\hline Multipara & 14604 & $0.59(86)$ & $0.88[0.60,1.28]$ & \\
\hline Parental socio-economic status at birth & & & & 0.47 \\
\hline Blue-collar worker & 9288 & $0.48(45)$ & 1.00 Reference & \\
\hline White-collar worker & 4126 & $0.87(36)$ & $1.80[1.11,2.91]$ & \\
\hline Self-employed worker & 2664 & $0.45(12)$ & $0.93[0.47,1.84]$ & \\
\hline Missing & 5526 & $0.72(40)$ & & \\
\hline
\end{tabular}

Table 1. Relative risk of polio according to perinatal characteristics of 21604 like-sexed Swedish twins born from 1926 to 1958

$n$ is the no. of persons at risk.

URR, unadjusted relative risk; CI, confidence interval.

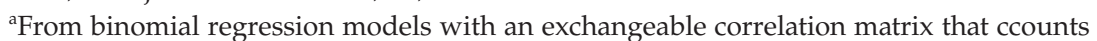
for within-twin pair correlations.

${ }^{b}$ Score test for each index variable versus an intercept-only model. P values represent tests for linear trends for all variables except for sex (Wald test). 
Table 2. Adjusted relative risk (RR) of polio according to anthropometric characteristics at birth of 21604 like-sexed Swedish twins born from 1926 to 1958

\begin{tabular}{lll}
\hline Variable & $R^{\mathrm{a}}[95 \% \mathrm{CI}]$ & $P$ \\
\hline $\begin{array}{l}\text { Birth length, cm } \\
\quad<44\end{array}$ & & \\
$44-46$ & $1.18[0.74,1.89]$ & \\
$47-49$ & 1.00 Reference & \\
$50-51$ & $1.25[0.79,1.96]$ & \\
$\geq 52$ & $0.84[0.36,1.95]$ & \\
Per $1 \mathrm{~cm}$ & $1.06[0.98,1.14]$ & 0.15 \\
Birthweight, g & & \\
$<2000$ & $0.58[0.22,1.53]$ & \\
$2000-2499$ & $1.04[0.66,1.65]$ & \\
$2500-2999$ & 1.00 Reference & \\
$3000-3499$ & $1.03[0.61,1.74]$ & \\
$\geq 3500$ & $1.04[0.41,2.61]$ & \\
Per 500 g & $1.34[0.99,1.82]$ & 0.06 \\
Head circumference, mm & & \\
$\quad \leq 319$ & $0.73[0.38,1.39]$ & \\
$320-329$ & $1.05[0.61,1.81]$ & \\
$330-339$ & 1.00 Reference & \\
$340-349$ & $1.20[0.72,1.99]$ & \\
$\geq 350$ & $1.18[0.63,2.03]$ & \\
Per 10 mm & $1.17[1.05,1.31]$ & 0.004 \\
\hline
\end{tabular}

CI, confidence interval.

${ }^{\text {a}}$ From binomial regression models with polio as the outcome and covariates that included each anthropometric variable plus sex, year of birth, and gestational age at birth. The model for birthweight was also adjusted for birth length. In all models, an exchangeable correlation matrix was specific to account for within-twin pair correlations.
However, results among monozygotic twins should not be susceptible to confounding and were in the same direction as those in the cohort analysis. Third, misclassification of the outcome is possible, as we relied on different data sources and could not check the consistency between them. In spite of the distinct neuropathological characteristics of polio, physician diagnosis and self-report may still be subject to error. Some studies in the 1940s and 1950s suggest that paralytic polio may have been underdiagnosed ${ }^{15,16}$ due to neglect of mild muscle weakness and insufficient duration of follow-up. Reported prevalence rates for post-polio syndrome have varied depending on length of follow-up and diagnostic criteria used. ${ }^{17-19}$ Evidence also suggests that non-paralytic polio was often misdiagnosed or underdiagnosed. ${ }^{20,21}$ Because any misclassification is unlikely to be related to exposure status in our study, misclassification bias could have attenuated the measures of association.

The inverse associations between some measures of intrauterine growth and incidence of polio need to be interpreted with caution. They could suggest that restricted fetal growth, a potential consequence of prenatal malnutrition due to nutritional and/or oxygen deprivation, may influence the development of later-life immune function in ways that decrease exposure and/or susceptibility to poliovirus. We cannot offer strong explanations for a potential 'programming' effect of the intrauterine environment on exposure to

Table 3. Differences in anthropometric characteristics at birth of twin pairs in a co-twin control analysis of polio risk

\begin{tabular}{|c|c|c|c|c|c|c|c|}
\hline \multirow[b]{2}{*}{ Variable } & \multicolumn{2}{|c|}{ Cases } & \multicolumn{2}{|c|}{ Controls } & \multirow{2}{*}{$\begin{array}{c}\text { Difference in } \\
\text { means (SD) }\end{array}$} & \multirow[b]{2}{*}{$P^{a}$} & \multirow{2}{*}{$\begin{array}{l}\text { Odds ratio } \\
{[95 \% \mathrm{CI}]^{\mathrm{b}}}\end{array}$} \\
\hline & $n$ & Mean (SD) & $n$ & Mean (SD) & & & \\
\hline \multicolumn{8}{|l|}{ All twins } \\
\hline Birth length $(\mathrm{cm})$ & 110 & $48.0(2.4)$ & 110 & $47.7(2.5)$ & $-0.3(2.0)$ & 0.19 & $1.14[0.91,1.42]$ \\
\hline Birthweight (g) & 113 & $2732(445)$ & 113 & $2648(484)$ & $-84(488)$ & 0.07 & $1.39[0.87,2.21]$ \\
\hline \multicolumn{8}{|l|}{ Monozygotic twins } \\
\hline Birth length $(\mathrm{cm})$ & 40 & $47.6(2.1)$ & 40 & $47.3(2.1)$ & $-0.3(1.8)$ & 0.47 & $1.21[0.84,1.74]$ \\
\hline Birthweight (g) & 42 & $2571(374)$ & 42 & $2494(385)$ & $-77(431)$ & 0.20 & $1.53[0.73,3.22]$ \\
\hline Head circumference (mm) & 39 & $328(12)$ & 39 & $325(17)$ & $-3(16)$ & 0.26 & $1.21[0.80,1.83]$ \\
\hline \multicolumn{8}{|l|}{ Dizygotic twins } \\
\hline Birth length $(\mathrm{cm})$ & 70 & $48.2(2.5)$ & 70 & $47.9(2.7)$ & $-0.3(2.2)$ & 0.29 & $1.14[0.91,1.42]$ \\
\hline Birthweight (g) & 71 & $2827(474)$ & 71 & $2739(515)$ & $-88(522)$ & 0.16 & $1.39[0.87,2.21]$ \\
\hline
\end{tabular}

SD, standard deviation; CI, confidence interval.

${ }^{a}$ Wilcoxon matched pairs rank-sumtest.

${ }^{\mathrm{b}}$ From conditional logistic regression models. Twin pairs are matched for shared environmental and genetic factors. OR is for every $500 \mathrm{~g}$ birth weight, $1 \mathrm{~cm}$ birth length, and $10 \mathrm{~mm}$ head circumference. 
poliovirus in Sweden. However, there could be mechanisms to explain long-lasting susceptibility to poliovirus infection due to the intrauterine environment, assuming that exposure was homogeneous in the population. Transmission of polio occurs through the oral ingestion of viral particles. In the small intestine, the virus infects microfold membrane cells ('M cells') located in the follicle-associated epithelium through CD155, ${ }^{22}$ the 'poliovirus receptor', which is expressed on the apicle and basolateral surfaces of these cells. ${ }^{23}$ Poliovirus is then transported from the gut directly to Peyer's patches, ${ }^{23}$ where the virus replicates and infects any other cells expressing CD155 including B lymphocytes and follicular dendritic cells. ${ }^{22}$ The virus may then enter the bloodstream, and eventually cross the bloodbrain barrier through retrograde axonal transport, ${ }^{24}$ or possibly directly from Peyer's patches by way of the vagus nerve. ${ }^{22,25}$ Since motor neurons express CD155, poliovirus infection and subsequent neuronal cell necrosis result in paralysis. ${ }^{26}$ Several studies suggest that intrauterine growth retardation may lead to inadequate development of the epithelial and mucosal defence system in the gut. ${ }^{27-29}$ Underdeveloped intestinal immunity would lead to increased susceptibility to most bacterial ${ }^{3}$ and viral ${ }^{30}$ infections. However, underdeveloped Peyer's patches and gut-associated lymphoid tissue may bear fewer cells expressing the CD155 poliovirus receptor, thus representing a disadvantage to poliovirus tropism. There are other enteroviruses that rely on gut-associated lymphoid tissue for entry and replication. For example, coxsackie viruses replicate in the upper respiratory tract, and the lymphoid tissue of the distal small bowel. ${ }^{31}$ Further studies of the associations between indicators of intrauterine growth and infection by other viruses are warranted.

We noted that the risk of polio was lowest in twins of the lowest birth length and $\mathrm{HC}$, but not necessarily in those of lowest birthweight. Because accrual of length occurs during the first 20 weeks of gestation, while weight gain reaches peak velocity at approximately 34 weeks of gestation, ${ }^{32}$ the decreased risk of polio among twins with birth length $<44 \mathrm{~cm}$ could indicate that poliovirus susceptibility may be related to intrauterine insults that happen earlier, rather than later, in pregnancy.

A substantial advantage of our study is that the co-twin control analysis by design controls for confounding by unmeasured shared environmental and genetic factors. In addition, differences in the postnatal anthropometric measurements within twin pairs provide insight into fetal growth. Another advantage is that the perinatal and parental sociodemographic characteristics were retrieved from original birth records, precluding recall bias. One limitation to our study is that the incidence of polio may not be representative of the actual rate of poliovirus infection. The gastrointestinal phase of poliovirus infection is associated with only mild disease symptoms, and only rarely (one in 100 infections) does poliovirus find its way into the central nervous system where it can cause the severe neuropathological complications that characterise poliomyelitis. ${ }^{22}$ Thus, our ascertainment of cases is reflective only of those who actually had manifestations of paralytic polio or late effects of acute poliomyelitis. In addition, some cases of polio in this study date prior to 1968, when ICD-7 diagnostic codes included only acute poliomyelitis and postpolio syndrome. Although ICD-8 through ICD-10 include diagnostic codes for acute non-paralytic polio, it is possible that twins who experienced only flu-like symptoms were less likely to seek medical treatment than those who were affected by paralytic polio; consequently, diagnoses for these participants would be missing from the Inpatient Registry. Finally, the generalisability of results from twin studies may be questionable, since twins are more growth-restricted and may differ in prenatal environment and upbringing than singletons. It is unknown whether the incidence of polio differs between twins and singleton-born children.

In conclusion, indicators of early intrauterine growth restriction were associated with decreased incidence of polio. If there is a causal effect of intrauterine environmental exposures on the 'programming' of the immune system to respond to infectious postnatal challenges, this effect is likely to vary according to the specific immune response elicited by the agent. While measures of intrauterine growth can be inversely related to the risk of infections that require a strong initial cellular response, such as tuberculosis, ${ }^{3}$ they could be positively related to viral infections that rely on mucosal and humoral immunity. Future studies to identify the immunological mechanisms that are susceptible to intrauterine programming are warranted. Examining the associations between indicators of intrauterine growth and the risk of other infectious diseases or autoimmune disorders may provide insights into specific immunological pathways that may be affected by perinatal conditions. 


\section{Acknowledgements}

This study was funded by grants from the Swedish Council for Working Life and Social Research (grants 2004-0174 and 2007-0231), the Swedish Research Council (grants K2006-71X-12676-04-2 and K2008-54X20638-01-3), the European Network of Excellence Lifespan (grant FP6 036895) and a University of Michigan Spring and Summer Research Grant (Wei Perng).

\section{References}

1 Moore SE, Cole TJ, Poskitt EM, Sonko BJ, Whitehead RG, McGregor IA, et al. Season of birth predicts mortality in rural Gambia. Nature 1997; 388:434.

2 Moore SE, Jalil F, Ashraf R, Szu SC, Prentice AM, Hanson LA. Birth weight predicts response to vaccination in adults born in an urban slum in Lahore, Pakistan. The American Journal of Clinical Nutrition 2004; 80:453-459.

3 Villamor E, Iliadou A, Cnattingius S. Evidence for an effect of fetal growth on the risk of tuberculosis. The Journal of Infectious Diseases 2010; 201:409-413.

4 Cooper AM. Cell-mediated immune responses in tuberculosis. Annual Review of Immunology 2009; 27:393-422.

5 Sorensen HT, Labouriau R, Jensen ES, Mortensen PB, Schonheyder HC. Fetal growth, maternal prenatal smoking, and risk of invasive meningococcal disease: a nationwide case-control study. International Journal of Epidemiology 2004; 33:816-820.

6 McDade TW, Beck MA, Kuzawa C, Adair LS. Prenatal undernutrition, postnatal environments, and antibody response to vaccination in adolescence. American Journal of Clinical Nutrition 2001; 74:543-548.

7 The Global Polio Initiative. Infected Countries [online]. 2010. http:/ / www.polioeradication.org/Infectedcountries.aspx [last accessed 12 March 2012].

8 Lichtenstein P, De Faire U, Floderus B, Svartengren M, Svedberg P, Pedersen NL. The Swedish Twin Registry: a unique resource for clinical, epidemiological and genetic studies. Journal of Internal Medicine 2002; 252:184-205.

9 Medlund P, Cederlof R, Floderus-Myrhed B, Friberg L, Sorensen S. A new Swedish Twin Registry containing environmental and medical base line data from about 14,000 same-sexed pairs born 1926-58. Acta Medica Scandinavica, Supplementum 1976; 600:1-111.

10 Lichtenstein P, Sullivan PF, Cnattingius S, Gatz M, Johansson S, Carlstrom E, et al. The Swedish Twin Registry in the third millennium: an update. Twin Research and Human Genetics 2006; 9:875-882.

11 Ludvigsson JF, Andersson E, Ekbom A, Feychting M, Kim JL, Reuterwall C, et al. External review and validation of the Swedish national inpatient register. BMC Public Health 2011; 11:450.

12 Statistics Sweden. Swedish Socioeconomic Classification. Stockholm: Statistics Sweden, 1982 [In Swedish].

13 Breslow NE, Day NE (eds). Statistical methods in cancer research. Vol 1. The analysis of case-control studies. IARC Scientific Publications 1980; 1:5-338.
14 Fagraeus A, Bottiger M. Polio vaccination in Sweden. Review of Infectious Disease 1980; 2:274-276.

15 Moskowitz E, Kaplan LI. Follow-up study in seventy-five cases of non-paralytic poliomyelitis. JAMA 1953; 152:1505-1506.

16 Shaw EB, Levin M. The infrequent incidence of nonparalytic poliomyelitis. Journal of Pediatrics 1954; 44:237-243.

17 Ramlow J, Alexander M, LaPorte R, Kaufmann C, Kuller L. Epidemiology of the post-polio syndrome. American Journal of Epidemiology 1992; 136:769-786.

18 Windebank AJ, Litchy WJ, Daube JR, Iverson RA. Lack of progression of neurologic deficit in survivors of paralytic polio: a 5-year prospective population-based study. Neurology 1996; 46:80-84.

19 Windebank AJ, Litchy WJ, Daube JR, Kurland LT, Codd MB, Iverson R. Late effects of paralytic poliomyelitis in Olmsted County, Minnesota. Neurology 1991; 41:501-507.

20 Bruno RL. Paralytic vs. 'nonparalytic' polio: distinction without a difference? American Journal of Physical Medicine $\mathcal{E}$ Rehabilitation 2000; 79:4-12.

21 Halstead LS, Silver JK. Nonparalytic polio and postpolio syndrome. American Journal of Physical Medicine $\mathcal{E}$ Rehabilitation 2000; 79:13-18.

22 Iwasaki A, Welker R, Mueller S, Linehan M, Nomoto A, Wimmer E. Immunofluorescence analysis of poliovirus receptor expression in Peyer's patches of humans, primates, and CD155 transgenic mice: implications for poliovirus infection. The Journal of Infectious Diseases 2002; 186: 585-592.

23 Kato T, Owen RL. Structure and function of intestinal mucosal epithelium. In: Function of Mucosal Immunologlobulins in the Handbook of Mucosal Immunology. Editors: Ogra PL, Mestecky J, Lamm ME, Strober W, McGhee JR, Bienenstock J. Orlando: Academic Press, 1994; pp. 127-137.

24 Ohka S, Yang WX, Terada E, Iwasaki K, Nomoto A. Retrograde transport of intact poliovirus through the axon via the fast transport system. Virology 1998; 250:67-75.

25 Wolf JL, Rubin DH, Finberg R, Kauffman RS, Sharpe AH, Trier JS, et al. Intestinal M cells: a pathway for entry of reovirus into the host. Science 1981; 212:471-472.

26 Ohka S, Matsuda N, Tohyama K, Oda T, Morikawa M, Kuge S, et al. Receptor (CD155)-dependent endocytosis of poliovirus and retrograde axonal transport of the endosome. The Journal of Virology 2004; 78: 7186-7198.

27 Nanthakumar N, Meng D, Goldstein AM, Zhu W, Lu L, Uauy $\mathrm{R}$, et al. The mechanism of excessive intestinal inflammation in necrotizing enterocolitis: an immature innate immune response. PLOS ONE 2011; 6:e17776.

$28 \mathrm{Neu}$ J, Chen M, Beierle E. Intestinal innate immunity: how does it relate to the pathogenesis of necrotizing enterocolitis. Seminars in Pediatric Surgery 2005; 14:137-144.

29 Rowe MI, Reblock KK, Kurkchubasche AG, Healey PJ. Necrotizing enterocolitis in the extremely low birth weight infant. Journal of Pediatric Surgery 1994; 29:987-990, discussion 990-981.

30 Moore SE, Cole TJ, Collinson AC, Poskitt EM, McGregor IA, Prentice AM. Prenatal or early postnatal events predict 
infectious deaths in young adulthood in rural Africa. International Journal of Epidemiology 1999; 28:1088-1095.

31 Harrath R, Bourlet T, Delezay O, Douche-Aourik F, Omar S, Aouni $\mathrm{M}$, et al. Coxsackievirus $\mathrm{B} 3$ replication and persistence in intestinal cells from mice infected orally and in the human CaCo-2 cell line. Journal of Medical Virology 2004; 74:283-290.

32 Tanner JM. Growth before birth. In: Fetus into Man. Editor: Tanner JM. Cambridge, MA: Library of Congress

Cataloging-in-Publication Data, 1990; pp. 38-49. 